\title{
Domestic violence: A hidden and deeply rooted health issue in India
}

\author{
Abantika Bhattacharya ${ }^{1}$, Mausumi Basu ${ }^{2}$, Palash Das ${ }^{3}$, Aditya Prasad Sarkar ${ }^{4}$, Prasanta Kumar Das ${ }^{5}$, \\ Biman Roy ${ }^{6}$
}

\begin{abstract}
${ }^{1}$ Assistant Professor; ${ }^{3}$ Associate Professor; Department of Community Medicine, Midnapore Medical College, Paschim Medinipur, West Bengal, India. ${ }^{2}$ Associate Professor; Department of Community Medicine, IPGMER, Kolkata, India. ${ }^{4}$ Associate Professor, Department of Community Medicine, Bankura Medical College, India. ${ }^{5}$ Associate Professor, Psychiatry, Medical College, Kolkata, India. ${ }^{6}$ Assistant Professor, Malda Medical College, West Bengal, India.
\end{abstract}

\begin{abstract}
Domestic violence was identified as a major contributor to the global burden of ill health in terms of female morbidity leading to psychological trauma and depression, injuries, sexually transmitted diseases, suicide and murder. The study was conducted to find out the prevalence of different types of life time domestic violence against women; factors associated with it and care seeking behavior. An observational cross-sectional study was done among 260 ever married women of 15-49 years of age using a predesigned pretested pro-forma from April 2011 to January 2012 by face to face interview. Data were compiled and analyzed by Epi Info 6 version and SPSS 17 version. The overall prevalence of any form of violence during the life time among the study population was $40.4 \%$. Verbal/ psychological violence was the most common form of domestic violence (85.7\%) followed by physical (71.4\%) and sexual violence $(57.1 \%)$. Slapping and or beating, kicking, object throwing were the major forms of physical violence; humiliation $(91.1 \%)$ was the commonest form of psychological violence and most common form of sexual violence was forced sexual intercourse (58.3\%). About $21 \%$ of the study population faced violence every day. Older age, lower age at marriage, longer duration of marriage, lower education of husband and wife, lower family income, unemployment of the husband and alcohol consumption of husband were associated with occurrence of domestic violence. We have found that the prevalence of domestic violence in this group of population is high. The alarming issue is that approximately one third of women (31.24\%) who faced violence in their life-time had never sought any help. The findings indicate to develop appropriate and culturally relevant public health interventions to increase awareness and implement policies regarding violence against women.
\end{abstract}

Keywords: Domestic violence, Married women, Socio-economic status, Care seeking behavior, India.

\section{Introduction}

The Fourth United Nations World Conference on Women 1995 in Beijing stated that violence against women (VAW) is a manifestation of the historically unequal power relations between men and women. ${ }^{1}$ United Nations declaration on the elimination of Violence against Women (VAW), in 1993, defined VAW as 'any act of gender-based violence that results in, or is likely to result in physical, sexual or psychological harm or suffering to women, including threats of such acts, coercion or arbitrary deprivation of liberty, whether occurring in public or in private life'.

The WHO Multi-country Study on 'Women's Health and Domestic Violence Against Women' indicated that the range of lifetime physical violence by a male, intimate partner, ranged from $13 \%$ in Japan to $61 \%$ in Peru with most sites falling between $23 \%$ and $49 \%$; range of lifetime prevalence of sexual violence by an intimate partner was between 6\% (Japan) and 59\% (Ethiopia) with most sites falling between $10 \%$ and $50 \%$; range of lifetime prevalence of physical or sexual violence, or both, by an intimate partner, was $15 \%$ to $71 \%$ with most sites ranged from $30 \%$ to $60 \%$. ${ }^{3}$ Likewise, regarding current violence -

\section{Practice Points}

- Violence against women is a significant public health problem in India.

- The overall prevalence of physical, psychological, sexual and any forms of violence among women were $71.4 \%, 85.7 \%, 57.1 \%$ and $40.4 \%$ respectively.

- Older age, lower age at marriage, longer duration of marriage, lower education of husband and wife, lower family income, unemployment of the husband and alcohol consumption of husband were associated with occurrence of domestic violence.

- The alarming issue is that approximately one third of women who faced violence in their lifetime had never sought any help.

- There is an need to develop appropriate and culturally relevant public health interventions to increase awareness and implement policies regarding violence against women.

Correspondence: Dr. Palash Das, MD, FAIMER Fellow, Associate Professor, Department of Community Medicine, Midnapore Medical College, Paschim Medinipur, West Bengal, India. E-mail: palashdasdr@gmail.com.

South East Asia Journal of Public Health 2013;3(1):17-23. (C) 2013 Bhattacharya et al., publisher and licensee Public Health Foundation Bangladesh. This is an Open Access article which permits unrestricted non-commercial use, provided the original work is properly cited. 
acts of physical or sexual violence in the year prior to being interviewed - range was between 3\% and 54\%, with most sites falling between $20 \%$ and $33 \%{ }^{3}$ The highest level of non-partner physical violence ranged between $10 \%$ to $62 \%{ }^{3}$ Commonly mentioned perpetrators included fathers, other family members and teachers. The highest levels of sexual violence by nonpartners ranged between 10\%-12\% in Peru, Samoa, and Tanzania city to $1 \%$ in Bangladesh and Ethiopia. ${ }^{3}$ The perpetrators included strangers, boyfriends, male family members (excluding fathers) or male friends of the family. Contrary to the common perception that women are more at risk of violence from strangers than from partners or other men they know; data showed that over $75 \%$ of women were abused by any perpetrator since the age of 15 years. ${ }^{3}$

The National Family Health Survey-III (NFHS-3) of India collected information from married and unmarried women age 15-49 years about their experience of physical and sexual violence which revealed that married women were more likely to experience violence by husbands than by anyone else and the prevalence was nearly $37 \%{ }^{4}$ It was also reported that spousal violence varied greatly by state; ranged from $6 \%$ in Himachal Pradesh to $59 \%$ in Bihar and $40.3 \%$ in West Bengal. ${ }^{4}$ Only one in four abused women have ever sought help to end the violence they have experienced. Only two percent of abused women have sought help from police. $^{4}$

Domestic violence is an underreported phenomenon in India including West Bengal, although West Bengal stands in the $8^{\text {th }}$ position according to the burden of domestic violence among all Indian states. ${ }^{4}$ A need was therefore felt for a community based study focusing on domestic violence against women (DVAW) to gather data that would improve our understanding of this 'sleeping giant'.

In this background, the present study was conducted with the objective of to find out the prevalence of different types of 'life time' domestic violence against ever married women in reproductive age group (15-49 years) in an urban area of a district of West Bengal, to identify the factors associated with it and also to estimate their care seeking behavior.

\section{Materials and methods}

A cross-sectional, community-based descriptive, and observational epidemiological study was carried out among all ever married women of 15-49 years of age residing at a slum of Alamgunje, Burdwan district of West Bengal, India from April 2011 to January 2012.

Inclusion criteria were all ever married women of 15 49 years of age, permanent residents of Alumgunje and willing to participate. Exclusion criteria were women below 15 years and above 49 years; mothers-in-law; unmarried; divorced and separated women; widows; non-cooperative women who refused to furnish necessary information; women who were seriously physi- cally or mentally ill; and visitors to that locality. Considering the prevalence of domestic violence as $41.8 \%,{ }^{4}$ confidence level of $95 \%, 15 \%$ relative precision and $10 \%$ non-response rate, the sample size was computed to be 297 .

A sampling frame of the above population was prepared with the help of urban health post. Sampling technique was census population. Study tool was a pre-designed pre-tested semi-structured interview schedule. The schedule was prepared in local language (Bengali) with the help of three experts of community medicine. The new tool was validated by three public health specialists. The pre-testing was done among the married women of the adjacent slum area and the women were not included in the sampling frame and minor modifications were done in the tool. Then the final tool was applied in data collection. Study variables were age in years, age at marriage, duration of marriage, religion, literacy status of study population, husband's education, occupation of study population, employment status of the husband, socio-economic status (as per Modified Kuppuswamy's Scale $2012^{6}$ ), prevalence, type and frequency of domestic violence, addiction of husbands to alcohol and their care seeking behavior.

\section{Procedure for Data collection}

Home visits were carried out, and face to face interview with these women was done in the absence of their guardian/husband by Principal Investigator (PI) and/or Co PIs. The purpose of the study was explained to the participants, informed consent was obtained and initial rapport was built with the help of female Community Leader. They were also assured that anonymity and strict confidentiality would be maintained. In case the sampled woman was not at home at the time of visit the next visit was scheduled after prior appointment. Information was gathered about socio-demographic profile of the participants and whether they were subjected to any domestic violence or not.

The interview lasted for 30-45 minutes depending on the women's experiences. The reference period considered was any time preceding the survey.

\section{Ethical permission}

Ethical permission was obtained from the Institutional Review Board of Burdwan Medical College, West Bengal, India.

\section{Statistical analysis}

Data were compiled and analyzed by Epi Info 6 version and SPSS 17 version. Proportions and chi-square tests were used for analysis of data. The $p$-value of less than 0.05 was considered as the minimum level of significance.

\section{Results}

The present study was conducted among ever married women of reproductive age group (15 to 49 years) in an urban area of Burdwan District. Out of 297 women, 260 were participated while $37(12.46 \%)$ refused because of 
feelings of shame and fear; thus the response rate was $87.54 \%$.

Mean age of the participants was $28 \pm 5.34$ years and majority of the women were in the age group of 25-35 years $(32.69 \%)$. All were Hindu and were currently in monogamous relationship during the time frame of preceding twelve months of the study. Regarding educational status, about half of the study population $(51.92 \%)$ were illiterate, and only $2.30 \%$ had studied up to higher secondary and above. Majority (92.31\%) of the respondents were home makers and rest $7.69 \%$ were unskilled laborers. With regard to socio-economic status (according to modified Kuppuswamy's Classification $\left.2012^{6}\right)$, a majority of the participants $(38.85 \%)$ belonged to the lower middle class. So far as occupation of husband was concerned, $87.69 \%$ were employed; $36.54 \%$ were unskilled laborers, $33.07 \%$ were skilled laborers, $4.61 \%$ were doing service and $13.47 \%$ were selfemployed. About $63.46 \%$ of the husbands of the study population were addicted to alcohol. A considerable number of husbands of participants $(32.69 \%)$ were illiterate and only $2.7 \%$ passed higher secondary and above. Majority (64.62\%) of the study population married after 18 years of age and $25.38 \%$ had married life for more than 10 years.

Prevalence of life time domestic violence as reported by the participants was high. In the present study, the overall prevalence of any form of violence during the life time among the study population was found to be $40.38 \%$ and husband was the main perpetrator followed by other family members .

Prevalence of different (physical, psychological, sexual) forms of life time domestic violence was assessed. Since the different types of violence were not mutually exclusive, women might report experiencing multiple forms of violence. Verbal/psychological violence was found to be the most common form of domestic violence $(85.71 \%)$ followed by physical $(71.43 \%)$ and sexual violence (57.14\%) among the subjects.

Slapping and or beating, kicking, throwing objects were the major forms of physical violence experienced by these women (Table 1). Humiliation $(91.11 \%$ ) was the commonest form of psychological violence. Most common sexual violence was use of physical force to have sexual intercourse $(58.33 \%)$.

The analysis of data indicates that the frequency of domestic violence was equitably distributed over different durations (Table 2). In response to frequency of domestic violence, the response of the participants was: every day $(20.95 \%)$, weekly $(19.05 \%)$, once in 15 days $(22.86 \%)$, monthly $(24.76 \%)$ and occasionally $(12.38 \%)$.

Association of different socio economic factors with prevalence of domestic violence was shown in Table 3. Prevalence of all forms of violence increased along with the age of the respondents. Women aged 25-35 years $(48.24 \%)$ and $35-45$ years $(49.23 \%)$ reported higher
Table 1: Types of physical, psychological and sexual violence

\begin{tabular}{|c|c|}
\hline Type of violence* & Respondents (\%) \\
\hline \multicolumn{2}{|l|}{ Physical violence (n-75) } \\
\hline Slapping/beating & $67(89.33 \%)$ \\
\hline Kicking & $54(72 \%)$ \\
\hline Object throwing & $30(40 \%)$ \\
\hline $\begin{array}{l}\text { Others (Chocking, punching, } \\
\text { threatening to kill) }\end{array}$ & $23(30.66 \%)$ \\
\hline \multicolumn{2}{|l|}{ Verbal/Emotional violence (n-90) } \\
\hline Humiliation & $82(91.11 \%)$ \\
\hline Blaming character of spouse & $78(86.7 \%)$ \\
\hline Threats to leave her & $68(75.55 \%)$ \\
\hline Dowry issues & $55(61.11 \%)$ \\
\hline Others & $40(44.44 \%)$ \\
\hline \multicolumn{2}{|l|}{ Sexual violence $(n-60)$} \\
\hline Pressure for sex & $35(58.33 \%)$ \\
\hline Hurt for sex & $31(51.66 \%)$ \\
\hline Others (angry when rejected) & $16(26.66 \%)$ \\
\hline
\end{tabular}

*Multiple responses

Table 2: Frequency of domestic violence

\begin{tabular}{|l|c|}
\hline \multicolumn{1}{|c|}{ Frequency } & $\begin{array}{c}\text { Respondents (\%) } \\
(\mathrm{n}-105)\end{array}$ \\
\hline Daily & $22(20.95 \%)$ \\
\hline Weekly & $20(19.05 \%)$ \\
\hline Fortnightly & $24(22.86 \%)$ \\
\hline Monthly & $26(24.76 \%)$ \\
\hline Occasionally & $13(12.38 \%)$ \\
\hline Total & 105 \\
\hline
\end{tabular}

prevalence of violence than women aged less than 25 years $(22.58 \%)$ and this difference was statistically significant $(\mathrm{p}<0.05)$.

Though no significant difference was found so far as literacy of both partners was concerned, the data revealed that education had an impact on the prevalence of domestic violence. The prevalence of violence decreased as educational levels of women and their husbands increased. About $42.22 \%$ of women with no education had experienced physical or sexual violence, as compared with $16.67 \%$ of women with 12 or more completed years of education. Similarly the women whose husbands were illiterate $(44.71 \%)$ faced more violence than women whose husbands had higher secondary and above $(14.29 \%)$. Study population with unemployed husbands reported more violence $(81.25 \%)$ than their counterparts with employed husbands $(34.65 \%)$ and the difference was statistically significant $(\mathrm{P}<0.05)$.

Socio-economic classification revealed that as the socio economic condition of respondents became better, prevalence of domestic violence decreased; women of lower SE class experienced $52.38 \%$ of violence whereas 
upper middle class women experienced $22.22 \%$ and this difference was also statistically significant $(\mathrm{p}<$ $0.05)$.

It was seen (Table 3 ) that as the age at marriage of the participants was increased $(76.09 \%$ for those who married before 18 years) the prevalence of domestic violence decreased $(48.21 \%$ for those who married at 18 years and more). It was also reported that as the duration of married life increased prevalence of domestic violence decreased; those who married for less than 5 years had experienced higher prevalence $(47.27 \%)$ of domestic violence than those married for more than 10 years $(27.27 \%)(p<0.05)$. Moreover, alcohol intake of husbands of the study population had a great impact on domestic violence; those husbands who were addicted to alcohol (57.58\%) experienced more violence than those without alcoholic husbands $(10.53 \%)$ which was again statistically significant $(p<0.05)$. About one third $(31.24 \%)$ of women who faced violence in their life-time had never sought any help (Table 4). More than $21.90 \%$ women sought help from their parents, followed by $16.19 \%$ from neighbors and only $6.67 \%$ had reported to police.

\section{Discussion}

Domestic violence is a global issue, reaching across national boundaries as well as socio-economic, cultural, racial and class distinctions. It is a widespread, deeply ingrained evil, which has serious impact on woman's health and well-being. ${ }^{7}$ In the present study, an attempt was made to get the overview of this social curse in an urban slum of Burdwan District of West Bengal, India.

Prevalence of Domestic violence

The present study identified that $40.4 \%$ had faced domestic violence in any form or in combination in their lifetime. India's National Family Health Survey-III, carried out in 29 states during 2005-06, found that nationwide, $37.2 \%$ of women experienced violence after mar-

Table 3: Scio-demographic characteristics and prevalence of domestic violence

\begin{tabular}{|c|c|c|c|}
\hline \multirow[t]{2}{*}{ Characteristics } & \multicolumn{2}{|c|}{ Experience of domestic violence } & \multirow{2}{*}{$\begin{array}{l}\text { Statistical } \\
\text { values }\end{array}$} \\
\hline & $\begin{array}{c}\text { Yes } \\
\text { Number (\%) }\end{array}$ & $\begin{array}{c}\text { No } \\
\text { Number (\%) }\end{array}$ & \\
\hline \multicolumn{4}{|l|}{ Age group (in years) } \\
\hline $18-25$ & $14(22.58 \%)$ & $48(77.42 \%)$ & \multirow{4}{*}{$\begin{array}{l}\chi^{2}=12.62 \\
(p<0.05)\end{array}$} \\
\hline $25-35$ & $41(48.24 \%)$ & $44(51.76 \%)$ & \\
\hline $35-45$ & $32(49.23 \%)$ & $33(50.77 \%)$ & \\
\hline$>45$ & $18(37.50 \%)$ & $30(62.5 \%)$ & \\
\hline \multicolumn{4}{|l|}{ Education of wife } \\
\hline Illiterate & $57(42.22 \%)$ & $78(57.78 \%)$ & \multirow{4}{*}{$\begin{array}{l}\chi^{2}=1.97 \\
(p>0.05)\end{array}$} \\
\hline Primary & $28(41.79 \%)$ & $39(58.21 \%)$ & \\
\hline Secondary & $19(36.54 \%)$ & $33(63.46 \%)$ & \\
\hline Higher Secondary and above & $1(16.67 \%)$ & $5(83.33 \%)$ & \\
\hline \multicolumn{4}{|l|}{ Education of husband } \\
\hline Illiterate & $38(44.71 \%)$ & $47(55.29 \%)$ & \multirow{4}{*}{$\begin{array}{l}\chi^{2}=5.08 \\
(p>0.05)\end{array}$} \\
\hline Primary & $41(44.57 \%)$ & $51(55.43 \%)$ & \\
\hline Secondary & $25(32.89 \%)$ & $51(67.11 \%)$ & \\
\hline Higher Secondary and above & $1(14.29 \%)$ & $6(85.71 \%)$ & \\
\hline \multicolumn{4}{|l|}{ Employment status of husband } \\
\hline Unemployed & $26(81.25 \%)$ & $6(18.75 \%)$ & \multirow{2}{*}{$\begin{array}{l}\chi^{2}=25.31 \\
(p<0.05)\end{array}$} \\
\hline Employed & $79(34.65 \%)$ & $149(65.35 \%)$ & \\
\hline \multicolumn{4}{|l|}{ Socio economic status } \\
\hline Upper middle & $2(22.22 \%)$ & $7(77.78 \%)$ & \multirow{4}{*}{$\begin{array}{l}\chi^{2}=9.65 \\
(\mathrm{p}<0.05)\end{array}$} \\
\hline Lower middle & $31(30.69 \%)$ & $70(69.31 \%)$ & \\
\hline Upper lower & $39(44.83 \%)$ & $48(55.17 \%)$ & \\
\hline Lower & $33(52.38 \%)$ & $30(47.62 \%)$ & \\
\hline \multicolumn{4}{|l|}{ Age at marriage (in years) } \\
\hline$>=18$ & $70(76.09 \%)$ & $22(23.91 \%)$ & \multirow{2}{*}{$\begin{array}{l}\chi^{2}=18.97 \\
(p<0.05)\end{array}$} \\
\hline$<18$ & $81(48.21 \%)$ & $87(51.79 \%)$ & \\
\hline \multicolumn{4}{|l|}{ Duration of marriage (in years) } \\
\hline$<5$ & $52(47.27 \%)$ & $58(52.73 \%)$ & \multirow{3}{*}{$\begin{array}{c}\chi^{2}=6.94 \\
(\mathrm{p}<0.05)\end{array}$} \\
\hline $5-10$ & $35(41.67 \%)$ & $49(58.33 \%)$ & \\
\hline$>10$ & $18(27.27 \%)$ & $48(72.73 \%)$ & \\
\hline \multicolumn{4}{|l|}{ Alcoholism of husband } \\
\hline Yes & $95(57.58 \%)$ & $70(42.42 \%)$ & \multirow{3}{*}{$\begin{array}{l}\chi^{2}=55.43 \\
(p<0.05)\end{array}$} \\
\hline No & $10(10.53 \%)$ & $85(89.47 \%)$ & \\
\hline Total & $105(40.38 \%)$ & $155(59.62 \%)$ & \\
\hline
\end{tabular}

South East Asia Journal of Public Health 2013;3(1):17-23 
Table 4: Care seeking behavior of victims

\begin{tabular}{|l|c|}
\hline \multicolumn{1}{|c|}{ Kind of help* } & $\begin{array}{c}\text { Respondents (\%) } \\
(\mathrm{n}-105)\end{array}$ \\
\hline Informed parents & $23(21.9 \%)$ \\
\hline Informed in-laws & $13(12.38 \%)$ \\
\hline Informed friends/neighbors & $17(16.19 \%)$ \\
\hline Informed police & $7(6.67 \%)$ \\
\hline Others (Professional help) & $8(7.62 \%)$ \\
\hline Did not seek help & $33(31.24 \%)$ \\
\hline
\end{tabular}

*Multiple responses

riage. ${ }^{4}$ A similar study conducted in a slum of Kolkata revealed that the prevalence of domestic violence was $54 \%{ }^{7}$ Another study in Siliguri showed that $78.2 \%$ women had experienced violence against them. ${ }^{8}$ A study on same topic done by Sarkar ${ }^{9}$ in rural setting of West Bengal showed prevalence of domestic violence was $23.4 \%$. Babu et al. ${ }^{10}$ reported the prevalence of domestic violence of $56.3 \%$ in Eastern India; $60.7 \%$ in Orissa, $51.8 \%$ in West Bengal and 58.9\% in Jharkhand respectively. A study by Jeyaseelan et al. ${ }^{11}$ in India showed $26 \%$ spousal physical violence during the lifetime of their marriage. The proportion of women who reported physical violence by their spouse was $26.6 \%$ in Goa; ${ }^{12}$ $39 \%$ in six zone of India; ${ }^{13}$ A total of $69 \%$ among nurses in AIIMS of Delhi; ${ }^{14} 42.8 \%$ in a colony of Del$\mathrm{hi}^{15}$ and $29.57 \%$ in Bangalore. ${ }^{16}$

These findings show local and regional variations; how local and regional authorities can take action efficiently and safely within their areas in three fields simultaneously: prevention, protection of victims and provision of services. Background characteristics such as education, age, marital duration, place of residence, caste, religion, sex of the head of the household, standard of living, work status of women, exposure to mass media and the autonomy of women with respect to decision making, freedom of movement and access to money are also linked to such variation of domestic violence.

\section{Prevalence of Different types of domestic violence}

In a study conducted in Uttar Pradesh by Koenig et al., ${ }^{17}$ the prevalence of lifetime physical and sexual violence was found to be $25.1 \%$ and $30.1 \%$ respectively, which was found to be higher (71.4\% and $57.1 \%$ respectively) in our study. The corresponding figures were $35.5 \%$ and $10.0 \%$ in NFHS III, ${ }^{4} 35.9 \%$ and $54.1 \%$ in Kolkata, ${ }^{7}$ $52.1 \%$ and $37.3 \%$ in Siliguri, ${ }^{8} 13.2 \%$ and $52.5 \%$ in Orissa, $14.6 \%$ and $50.6 \%$ in West Bengal, $21.2 \%$ and $54.5 \%$ in Jharkhand, $16.1 \%$ and $52.3 \%$ in Eastern India, ${ }^{10} 43.3 \%$ and $30 \%$ among nurses in AIIMS; ${ }^{14} 14 \%$ and $14 \%$ in six zone; ${ }^{15} 31.6 \%$ and $10.5 \%$ in Bangalore, ${ }^{16}$ and $84 \%$ and $90 \%$ in a study on five adjoining states of Andhra Pradesh, Chhattisgarh, Gujarat, Madhya Pradesh and Maharashtra. ${ }^{18}$

In the present study women also suffered from more than one type of violence. This was similar with the findings of other studies ${ }^{4,14,18}$ where the reported violence was multiple in nature and most of the women were subjected to more than one type of violence.

\section{Different forms of physical, psychological and sexual} violence

The most common form of lifetime physical violence was slapping and/beating (89.3\%), kicking (72\%), object throwing $(40 \%)$, choking and punching the women $(30.6 \%)$ which was consistent with the findings of other studies. ${ }^{4,8-10,12,14,18}$ According to NFHS III most common physical violence was slapping (34\%) followed by twisting of arms or pulling of hairs $(15.4 \%)$, throwing something (14\%), kicking (12\%) and choking $(2 \%)$. Humiliation was the most common form of emotional violence in this study and other studies. ${ }^{4,9,12}$ Most common form of sexual violence was physically forced her to have sexual intercourse $(58.3 \%))^{4,9}$

\section{Frequency of domestic violence}

In the five state study, ${ }^{18}$ about $16 \%$ of women reported that they were facing domestic violence once or twice in a week, or once or twice in a month and the percentage of respondents against whom domestic violence was committed practically every day was $15 \%$; which was similar to the present study. In Singur, the study also found that $9.1 \%$ faced violence few times in a week or few times in a month whereas $81.8 \%$ faced it in a year. In Bangalore study, the frequency of violence was at least once in a week in $34.21 \%$ women, once in 15 days in $31.58 \%$ women, once in a month in $26.32 \%$ and once in $1-3$ months in $7.89 \%$ women. $^{16}$

\section{Relation of Domestic Violence with socio-demographic variables}

Age had a profound association with the prevalence of domestic violence. Prevalence of all forms of violence was increased along with the increasing age of the women in the present study and other studies also ${ }^{4,9,10,}$ $12,13,15$ but Bangalore study ${ }^{16}$ didn't reveal this association where it was observed that as age of the women increased the prevalence of domestic violence decreased.

Among other socio-demographic variables examined, education had impact on the prevalence of domestic violence which was inversely associated with education levels of the women and their husbands and it was corroborative with the findings of some other studies. ${ }^{4-9}$ ${ }^{14,18}$ The reason may be that a well-educated woman is most likely to have a better or equally qualified husband and also more autonomy in partner selection which minimizes her risk of intimate partner violence (IPV). However though violence decreases with increase of education, the magnitude of domestic violence (DV) was considerably high among women with higher literacy also. In this study, families with low -income level showed a higher rate of violence and the rate of domestic violence decreased as the socio-economic level increased; some other studies also supported this finding. ${ }^{4,9,11-13}$ However, these studies ${ }^{4,9,11}$ -13 also revealed that higher levels of education among both husbands and wives and greater household wealth were found to be protective factors against the risk of 
spousal violence.

Role of alcohol in potentiating IPV was notorious. Alcohol addiction of the husband was found to be strongly related to the presence of domestic violence in this study and other studies. ${ }^{4,7,11-14,16}$ NFHS III reported that women whose husbands drink alcohol had significantly higher rates of violence than women whose husbands did not drink at all; emotional violence was three times as high, physical violence was more than two times as high, and sexual violence was four times as high. ${ }^{4}$ It was seen that conflict escalates into violence more readily when alcohol has been consumed because alcohol is a psychopharmacological dis-inhibitor. However, the high prevalence of spousal violence even among women whose husbands do not consume alcohol indicates that alcohol consumption is not the only explanation for the high prevalence of spousal violence in India. ${ }^{4}$

Majority of the victimized women preferred to be silent sufferers. The help seeking behavior was found in one third $(31.5 \%)$ of women who had faced violence in their lifetime. These women had never sought any help, even from their relatives and close friends, and preferred to rely upon their own strategies to deal with the situation. This was corroborative to some other studies ${ }^{12,14}$ where $32.7 \%$ and $74.4 \%$ respectively did not report the abusive situations in which they were living.

Abused women most often seek help from their own families. In our study $21.9 \%$ women sought help from their parents, followed by $16.2 \%$ from friends/neighbors while only $6.7 \%$ had reported to police which represented the tip of the iceberg. A similar study at North Bengal $^{8}$ revealed that $74.9 \%$ never sought for any help; $13.9 \%$ sought for first aid, $4.9 \%$ sought for professional help, $3.6 \%$ reported to police. The NFHS III data also corroborated with it, where only $36.7 \%$ sought help, $71 \%$ mentioned their own family as a source. Notably few women seek help from any institutional sources such as the police, medical personnel or social service organizations. ${ }^{4}$ In the five state study, among the respondents who sought help, $26.3 \%$ abused women had approached their parents, $15.6 \%$ to relatives and $57.9 \%$ to friends. ${ }^{18}$ Goa study revealed that $31.1 \%$ talked to relatives or close friends and only $4.4 \%$ took legal help. ${ }^{12}$ In the Bangalore study, nobody informed the police. ${ }^{16}$ This was because women were socialized to accept, tolerate and even rationalize domestic violence, and to remain silent about such experiences. Often they had the idea that it belonged to their husbands' right to beat their wives. The present study and some other studies highlighted the factors which had positive influence for domestic violence like young age at marriage, ${ }^{12,16,18}$ duration of marriage, ${ }^{4,14}$ as well as husband's employment status. ${ }^{14}$

The effects of violence on a victim's health are severe. Domestic violence can lead to serious short- and longterm physical, mental, sexual and reproductive health problems for women and lead to high social and economic costs. ${ }^{19,20}$ In addition to the immediate injuries, victim may suffer from chronic pain, gastrointestinal disorders, psychosomatic symptoms, and eating problems. ${ }^{20}$ Domestic violence is associated with mental health problems such as anxiety, post-traumatic stress disorder, and depression. Intimate partner violence in pregnancy also increases the likelihood of unplanned or early pregnancies and sexually transmitted diseases, miscarriage, stillbirth, pre-term delivery and low birth weight babies. ${ }^{19.20}$

The evidence highlights the urgent need to address the various economic and socio-cultural factors that foster a culture of violence against women in India. Policies and guideline should be develop to challenge the social norms which support male authority and control over women and encourage violence against women by strengthening women's human and economic rights and reducing gender gaps in relation to employment and education.

\section{Limitations of the study}

The sensitivity and stigma associated with violence, as well as fear of reprisal, may lead to under-reporting of violence. Recall bias may be present in disclosing the violent episodes. Cross-sectional design which did not allow for making conclusions focused on associations. A small sample size has limited the generalizability of the present study. Investigation of the effects of violence on health would provide a clearer picture of shortand long-term suffering of the victims.

\section{Conclusion}

As an overall, over $50 \%$ of the teachers having high The present study found that the overall prevalence of physical, psychological, sexual and any forms of violence among women were $71.4 \%, 85.7 \%, 57.1 \%$ and $40.4 \%$ respectively. The findings showed higher prevalence of domestic violence among slum population, compared to the NFHS III observations in the general population. The study revealed the high prevalence of all forms of violence against women in an urban area of Burdwan, India. Older age, lower age at marriage, longer duration of marriage, lower education of husband and wife, lower family income, unemployment of the husband and alcohol consumption of husband were associated with occurrence of domestic violence.

Ending violence against women needs to be addressed at various levels. The coordinated efforts of various sectors such as social, legal, educational, medical etc. are essential to address the various economic and sociocultural factors that foster a culture of violence against women in India by strengthening women's human and economic rights and reducing gender gaps in relation to employment and education.

\section{References}

1. United Nations. Report of the Fourth World Conference on Women, Beijing, 4-15 September 1995. New York: United Nations, 1996. 
2. United Nations. United Nations Declaration on the Elimination of Violence against Women, (A/ RES/48/104-85th plenary meeting - 20 Dec 1993, General Assembly: Article 1, 2). http:// www.un.org/documents/ga/res/48/a48r104.htm (accessed June 2013)

3. Garcia-Moreno C, Jansen HAFM, Ellsberg M, Heise L, Watts C. WHO multi-country study on women's health and domestic violence against women: initial results on prevalence, health outcomes and women's responses. Geneva: World Health Organization, 2005.

4. International Institute for Population Sciences (IIPS) and Macro International. National Family Health Survey (NFHS-3), 2005-06: India: Volume I. Mumbai: IIPS, 2007.

5. Stephenson R. Human immunodeficiency virus and domestic violence: the sleeping giants of Indian health? Indian J Med Sci 2007; 61:251-2.

6. Kumar N, Gupta N, Kishore J. Kuppuswamy's socioeconomic scale: Updating income ranges for the year 2012. Indian J Public Health 2012;56:103-4.

7. Sinha A, Mallik S, Sanyal D, Dasgupta S, Pal D, Mukherjee A. Domestic violence among ever married women of reproductive age group in a slum area of Kolkata. Indian $J$ Public Health 2012;56:31-6.

8. Ray K, Chakraborty M, Roy H, Gupta S, Banerjee I. 'Violence against Women': Evidence from a Cross Sectional Study in Urban Area of North Bengal. Al Ameen J Med Sci 2012;5:157-64.

9. Sarkar M. A study on domestic violence against adult and adolescent females in a rural area of West Bengal. Indian $J$ Community Med 2010;35:311-5.

10. Babu BV, Kar SK. Domestic violence against women in eastern India: a population-based study on prevalence and related issues. $B M C$ Public Health 2009,9:129.

11. Jeyaseelan L, Kumar S, Neelakantan N, Peedicayil A, Pillai R, Duvvury N. Physical spousal violence against women in India: Some risk factors. J Biosoc Sci 2007;39:657-70.

12. Kamat U, Ferreira AMA, Motghare DD, Kamat N, Pinto NR. A cross-sectional study of physical spousal violence against women in Goa. Health Line 2010;1:34-40.

13. Mahapatro M, Gupta RN, Gupta V. The risk factor of domestic violence in India. Indian J Community Med 2012;37:153-7.

14. Sharma KK, Vasta M. Domestic violence against nurses by their marital partners: A facility-based study at a tertiary care hospital. Indian J Community Med 2011;36: 222-7.

15. Vachher AS, Sharma AK. Domestic violence against women and their mental health status in a Colony in Delhi. Indian $J$ Community Med 2010;35:403-5.

16. Gaikwad V, Madhukumar S, Sudeepa D. An epidemiological study of domestic violence against women and its association with sexually transmitted infections in Bangalore Rural. Online $J$ Health Allied Sci 2011;10:1-3.

17. Koenig MA, Stephenson R, Ahmed S, Jejeebhoy $\mathrm{SJ}$, Campbell J. Individual and contextual determinants of domestic violence in North India. Am J Public Health 2006 ;96:132-8.

18. Yugantar Education Society, Civil Lines, Sadar, Nagpur. Research study report: A study of nature, extent, incidence and impact of domestic violence against women in the states of Andhra Pradesh, Chhattisgarh, Gujarat, Madhya Pradesh and Maharashtra. Submitted to Planning Commission, Government of India, New Delhi, 2003.

19. WHO. Violence against women. Intimate partner and sexual violence against women. Fact sheet N²39. Geneva: World Health Organization, 2013.

20. The Advocates for Human Rights. Health Effects of Domestic Violence. http://www.stopvaw.org/ health_effects_of_domestic_violence (accessed June 2013) 